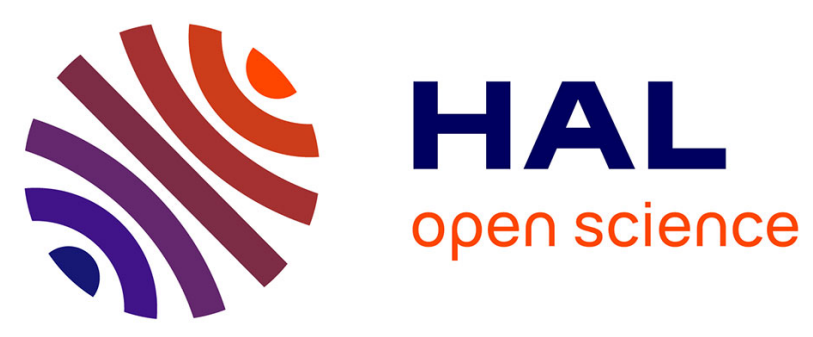

\title{
Anti-Bacterial Action of Plasma Multi-Jets in the Context of Chronic Wound Healing
}

Thomas Maho, Raphaelle Binois, Fabienne Brulé-Morabito, Maryvonne

Demasure, Claire Douat, Sébastien Dozias, Pablo Escot Bocanegra, Isabelle

Goard, Laurent Hocqueloux, Claire Le Helloco, et al.

\section{To cite this version:}

Thomas Maho, Raphaelle Binois, Fabienne Brulé-Morabito, Maryvonne Demasure, Claire Douat, et al.. Anti-Bacterial Action of Plasma Multi-Jets in the Context of Chronic Wound Healing. Applied Sciences, 2021, 11 (20), pp.9598. 10.3390/app11209598 . hal-03404153

\section{HAL Id: hal-03404153 \\ https://hal.science/hal-03404153}

Submitted on 26 Oct 2021

HAL is a multi-disciplinary open access archive for the deposit and dissemination of scientific research documents, whether they are published or not. The documents may come from teaching and research institutions in France or abroad, or from public or private research centers.
L'archive ouverte pluridisciplinaire HAL, est destinée au dépôt et à la diffusion de documents scientifiques de niveau recherche, publiés ou non, émanant des établissements d'enseignement et de recherche français ou étrangers, des laboratoires publics ou privés. 


\title{
Anti-bacterial action of plasma multi-jets in the context of chronic wound healing
}

\author{
Thomas Maho', Raphaelle Binois², Fabienne Brule-Morabito ${ }^{3}$, Maryvonne Demasure ${ }^{2}$, Claire Douat ${ }^{1}$, Sébastien \\ Dozias1, Pablo Escot Bocanegra ${ }^{1}$, Isabelle Goard ${ }^{2}$, Laurent Hocqueloux ${ }^{2}$, Claire Le Helloco ${ }^{2}$, Inna Orel ${ }^{1}$, Jean-Michel \\ Pouvesle ${ }^{1}$, Thierry Prazuck ${ }^{2}$, Augusto Stancampiano ${ }^{1}$, Clément Tocaben ${ }^{1}$ and Eric Robert ${ }^{1}$ * \\ 1 GREMI, UMR7344, CNRS/Université d'Orléans 45067 Orléans Cedex 2, France \\ 2 Centre Hospitalier Régional d'Orléans, 14 Av. de l'Hôpital, 45100 Orléans, France \\ 3 Centre de Biophysique Moléculaire (CBM), CNRS UPR 4301, 45071 Orléans, France \\ * Correspondence: eric.robert@univ-orleans.fr
}

Featured Application: The objective of the work is to assess the use of non-thermal multi plasma jets for the treatment of infected and chronic wounds in the context of hospital centers.

\begin{abstract}
This work is a contribution to the development and implementation of non-thermal plasma technology for decontamination in the perspective of nosocomial and chronic wound innovative therapies. Multi jets devices based on Plasma Gun $®$ technology in static and scanning operation modes and bacterial lawns inoculated with resistant and non-resistant bacterial strains were designed and used. A pilot toxicity study exploring plasma treatment of wound bearing patients, performed with a low voltage plasma applicator, is documented as a first step for the translation of in vitro experiments to clinical care. Bacterial inactivation was demonstrated for Staphylococcus aureus, Pseudomonas aeruginosa and drug resistant S. aureus, P. aeruginosa and Escherichia Coli strains collected from patient's wound at Orleans (France) hospital. Few square centimeter large contaminated samples are inactivated following a single plasma exposure as short as one minute. Samples inoculated with a single but also a mix of three resistant pathogens, were successfully inactivated not only right after their contamination but for mature lawns as well. Similar bactericidal action was demonstrated for antibiotic-resistant and non-resistant $P$. aeruginosa. The time exposure dependent increase of the inhibition spots, following multi jets exposure, is discussed as either the accumulation of reactive species or the likely combinatory action of both the reactive species and transient electric field delivery on inoculated samples.
\end{abstract}

Keywords: plasma jets, non-thermal plasma, plasma decontamination, resistant pathogen, wounds, plasma medicine, Escherichia Coli, Staphylococcus aureus, Pseudomonas aeruginosa, multidrug-resistant bacteria.

\section{Introduction}

As introducing new people to "plasma" as "ionized gas", one mentions that plasma is the fourth state of matter and represents more than $99 \%$ of the baryonic matter of the universe. Natural plasmas are fascinating (aurora), a unique source of energy on earth (sun power), at the origin of basic mater physics (stars, quark plasma, amino acid generation as the bricks of life), but they are also somehow "hostile", generating huge transient current and overvoltage in lightning, electromagnetic disturbance in the pole region, intense energetic radiation fluxes constraining microorganisms and life expansion. This was indeed one the first historical development of plasma science and technology to try to benefit from the radiative (UV, X-rays) and chemical compounds (oxidants, metastable states, charged particles with high energy) of plasmas for decontamination or sterilization purposes. Besides pioneer works [1-3] and industrial devices development [4,5] based on plasma generation, innovative ongoing research works are still continuously reported on 
this topic [6-9]. New eco-friendly alternatives pushed by consumer needs and environmental challenges, such as the use of natural ingredients for cosmetics, the design of innovative food product packaging, food product shelf life lengthening but also the emergence of antibiotics resistant pathogens or new viruses are key examples among others, where an increasing need for new decontamination strategies are continuously required. Many among them are based on plasma technology [10-13]. Indeed, plasma are known to be a potential and likely unique strategy for resistant microorganism's reduction, mostly due to plasma's multifaceted features, merging energetic radiation, energetic particles, and chemically active compound cocktail likely combining short and long-lived oxidants.

In this context, non-thermal plasma, or so-called cold plasma, have been developed in the past decade for plasma biomedical applications. Among them, the therapeutic applications in "Plasma medicine" [14,15] emerge, within at least the two probably more advanced fields being wound care [16-23] and new approaches for cancer treatment [2431].

Clinical studies dedicated to wound healing indicate that pathogen abatement, tissue growth stimulation and immune response are three of the modes of action that plasma delivery can trigger and control. Pathogen reduction is a key issue in hospitals where more and more multidrug-resistant strains of bacteria are emerging thus limiting or even preventing the use of conventional disinfectants or drugs. Brun et al [32] reported on plasma antibacterial effect with an RF helium afterglow on multi resistant Pseudomonas aeruginosa and methicillin-resistant Staphylococcus aureus exposed in vitro samples. Planktonic or biofilm growth on borosilicate slides cultured in 24-well plates were considered in this work and combination of plasma treatment with antibiotics was also evaluated. In [33], a dielectric barrier discharge (DBD) plasma torch generated with an air flow at 3.5 $\mathrm{L} / \mathrm{min}$ and delivering a plasma jet $4 \mathrm{~mm}$ in diameter was used to study the sensitivity of antibiotic-resistant and non-resistant bacteria. The microorganisms were set in a thin liquid layer covering a glass substrate. Authors conclude that plasma degrades components (DNA) of the bacteria so that the plasma method may be useful in eliminating bacteria that are recalcitrant to conventional antibiotic therapy. Application of DBD plasma was also demonstrated as a valuable decontamination technique for the removal from inert surfaces of planktonic and biofilm-embedded bacteria such as methicillin-sensitive $S$. aureus (MRSA-USA 300, MRSA-USA 400), and E. coli, the most common hospital contaminants. [34]. Plasma source named FlatPlaSter2.0. consisting of surface micro-discharges generated in air over a surface of $13 \times 9 \mathrm{~cm}^{2}$ was assessed as an alternative disinfectant for dry surfaces [35]. Bacterial endospores including Clostridium difficile and vegetative bacteria including Enterococcus faecium were considered. It was concluded that air plasma can disinfect dry inanimate surfaces contaminated with bacteria including bacterial endospores. The effect was mainly limited by the bacterial density. The perspective enlightened that plasma could serve as an alternative in the disinfection of medical instruments complementary to the standard cleaning procedures. He et al [36] reported on the sensitivity of two drug-resistant bacteria to low-temperature air plasma in catheter-associated urinary tract infections. Low temperature air plasma demonstrated efficiency to decontaminate resistant E. coli and Enterococci through the destruction of the ribosome and other organelles inside the bacteria. Besides all these above evoked plasma and plasma afterglow treatments, two other protocols can be envisioned for decontamination applications. They consist in plasma treated solution delivery or aerosol injection in combination with plasma discharge $[37,38]$. Indeed, in the COVID pandemics context and in the perspective of future applications in controlling the microbiota in tubes and tracheal appliances used in the respiratory tract, the anti-microbial efficacy of nebulized plasma activated water applied for 15 min shows the inactivation of S. aureus and E. coli [39].

Publications dealing with resistant micro-organisms in the context of clinical protocol are much more scarce. Nevertheless, Daeschlein et al [40] demonstrated that argon-based cold atmospheric plasma can serve as a potent treatment modality to reduce, even eradicate numbers of multidrug resistant pathogens colonizing patient's wounds. This outstanding and probably pioneer work was performed with a "plasma cold beam" fed at 6 
$\mathrm{L} / \mathrm{min}$ with argon and resulting in a target plasma spot of about $5 \mathrm{~mm}$ in diameter. Heinlin et al [41] reviewed plasma applications in medicine with a special focus on dermatology. Among various topics, they report 291 treatments in 36 patients, and found a highly significant reduction in bacterial load in wounds treated with argon plasma compared with untreated wounds. This reduction was found in all types of bacteria, even in multidrugresistant bacteria such as methicillin-resistant Staphylococcus aureus (MRSA). Following theses encouraging reports nowadays exists a great interest in developing dedicated nonthermal plasma sources efficient and easy to implement in hospital or medical centers to face the critical challenges of nosocomial infection and chronic wounds.

In this work, preliminary results are documented on the use of non-thermal plasma jets for bacterial load reduction in the context of chronic wound therapy. The following section presents the various plasma multi jet devices developed for this work and the bacterial targets used for the evaluation of the plasma decontamination opportunities. Then, in vitro decontamination assessments are presented and discussed for various pathogens including resistant strains collected from patients at the Orleans hospital (CHRO). Finally, preliminary results obtained with low voltage plasma jets in the context of the toxicity evaluation for patients' treatment through a pilot study undergone at Orleans Regional Hospital in the department of Tropical and Infectious Diseases are briefly introduced.

\section{Materials and Methods}

\subsection{Plasma jet devices}

This work is based on the use of non-thermal plasma devices for in vitro applications and a pilot study. Based on our know-how at GREMI, the plasma gun technology [42, 43] was used in this work having in mind the two main requirements: to develop plasma jets keeping the temperature of the target sample below $40{ }^{\circ} \mathrm{C}$ and to afford the best strategy to expose large contaminated surfaces during short time treatments. In the perspective of the treatment of infected and chronic wounds, the typical surfaces to be exposed are of a few to tens of square centimeters large and exhibit structured three dimensional topologies, i.e. they do not necessarily consist in flat targets. Thus, the whole surface exposure should be performed with likely significant variations of the distance between the plasma jet and the sample and the full time treatment should not exceed a few minutes.

The first option, recently reported in [44], is to expose large surfaces to room temperature single plasma jet powered with high frequency (typically 10 to $20 \mathrm{kHz}$ with our device) voltage pulses of microsecond duration. The tuning of the voltage peak amplitudes, gas flow rate and the consideration of the target electrical conductivity features, was demonstrated to allow for the controlled exposure of surface with a typical diameter of $2 \mathrm{~cm}$ in diameter. Nevertheless, first larger surface exposure was not easy to achieve without an additional displacement of the plasma plume, and second this device was to be operated at voltages ranging from 10 to $20 \mathrm{kV}$.

The second option consists in the operation of so-called multi-jets generated from a single primary jet $[43,45,46]$. These multi-jets were used for the in vitro study performed in this work with two applicators: the one delivering multi-jets in ambient air leading to a multi spot impact, the other with using the same device but with an additional sleeve leading to helium accumulation over the target, while not being fully air tight to keep reactive oxygen and nitrogen species generation. This second applicator results in plasma delivery as a combination of multi spots and a diffuse plasma generated in between the individual jets. These two multi-jets devices are called "multi-spot" and "diffuse mode" applicators in the following. The figure 1 presents the schematic of these two devices.

As shown in figure 1, any of the two plasma applicators was connected through a flexible silicone tube inside which high purity $(99.999 \%)$ helium was flushed at $4 \mathrm{~L} / \mathrm{min}$. The pulse power supply generates voltage pulses of $4 \mu \mathrm{s}$ FWHM having a peak amplitude of $+14 \mathrm{kV}$ and delivered at $2 \mathrm{kHz}$ repetition rate. These voltage pulses are delivered via an isolated copper wire inserted all along the silicone tube to the tip located at the inlet of the shower-like multi-jets applicator schematically documented in Fig.1. This remote plasma 
jet generation including a flushed gas and high voltage wire inside a flexible tube was previously reported for endoscopic application [47] and multi-jets generation [48]. The shower-like applicator consists in a dielectric (Delrin $\left.{ }^{\circledR}\right)$ assembly having an inlet volume (50 $\mathrm{mm}$ in diameter, $20 \mathrm{~mm}$ height), and an outlet part equipped with 52 channels $(0.8$ $\mathrm{mm}$ in diameter, $10 \mathrm{~mm}$ height). These 52 channels are distributed along four rings of 8 , 18, 28 and $38 \mathrm{~mm}$ in diameter and having 4, 12, 12 and 24 holes respectively. The discharge is ignited at the tip of the high voltage wire, as a primary helium plasma jet. This primary plasma jet propagates in the inlet volume of the shower-like applicator before splitting in secondary helium jets generated in the channels of the outlet section of the applicators [46]. With the multi spot plasma applicator, all the secondary jets distributed along the $8,18,28$ and $38 \mathrm{~mm}$ in diameter rings were delivered simultaneously. The plasma in contact with the sample is associated with ionization wave propagation in the helium gas flow at the outlet of the capillary.
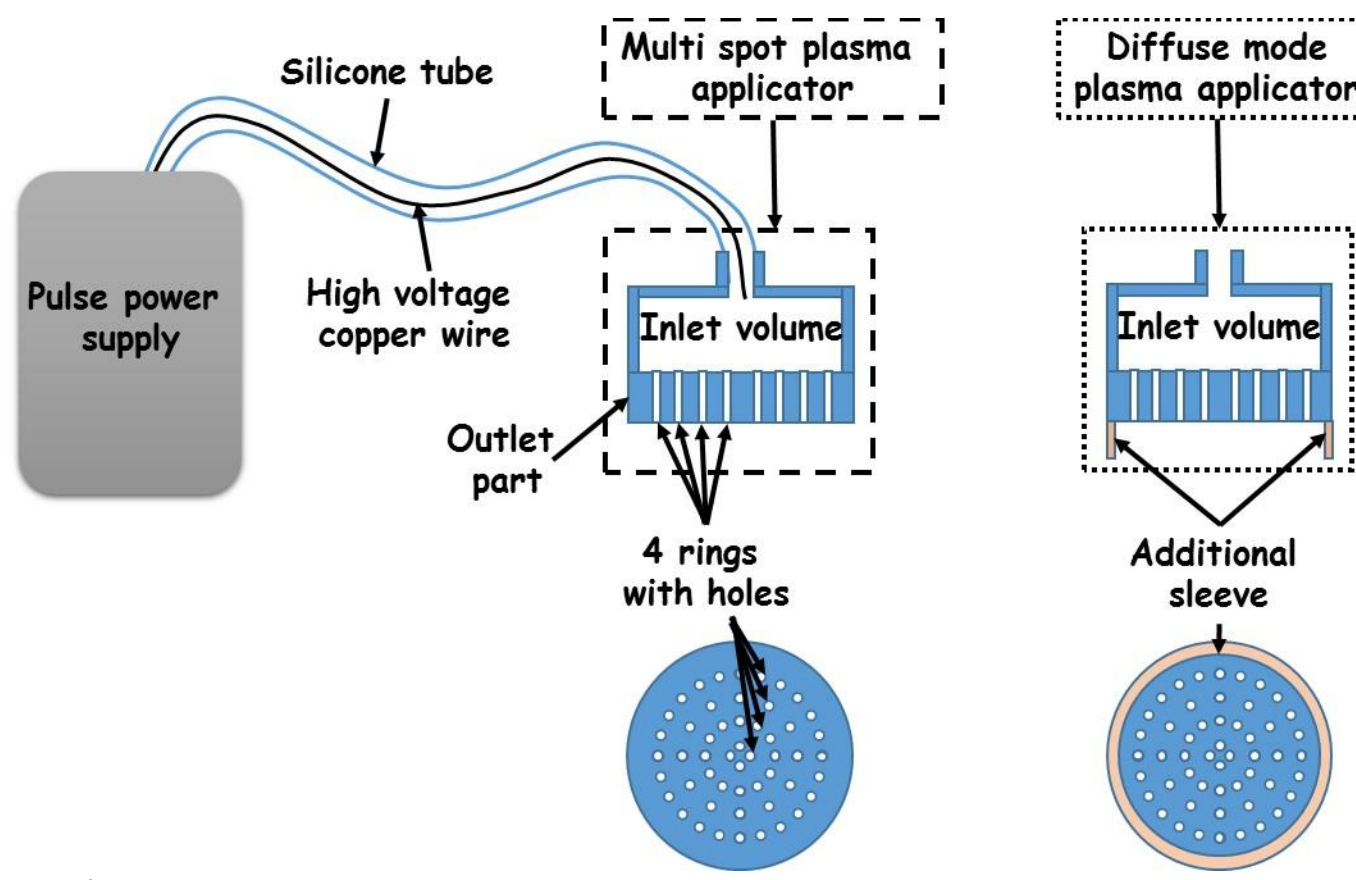

Figure 1 Schematic of the multi-jets devices (option 2) with pulse power supply, high voltage wire inside the silicone and center: multi-spot, and right: diffuse mode applicators. On bottom end on view of the applicators. When operated, the silicone tube connection for the diffuse mode applicator is the same as for the multi-spot applicator.

The third option consists in the generation of multi-jets in a bunch of individual helium flushed capillaries, each equipped with an inner needle-like powered electrode, and a grounded ring electrode surrounding all the $4 \mathrm{~mm}$ inner diameter, $3 \mathrm{~cm}$ long dielectric capillaries. The short distances between the needle tip and the capillary outlets (5 $\mathrm{mm}$ in this work) and the short gap from the capillary outlet to the samples (a few $\mathrm{mm}$ in this work) allow to generate the multi-jets with voltage pulses of lower peak amplitudes of 2 $\mathrm{kV}$. This low voltage operation enables the use of a more compact and lower power consuming pulsed power supply and operation at higher pulse repetition rate $(20 \mathrm{kHz}$ in this work) while keeping the input power to the multi-jets applicator in the range of a few Watts. Another key advantage of this third class of multi-jets, as was shown, is that the distance to samples is much less critical for each individual jet generation over non-flat targets, much representative of chronic wounds. In a first step, this type of device has been used for the pilot study in a single jet configuration as will be described in the result section. The multi-jets configuration for the generation of four secondary jets is shown in figure 2. This third class of multi-jets device is called the "low voltage" plasma applicator in the following. 

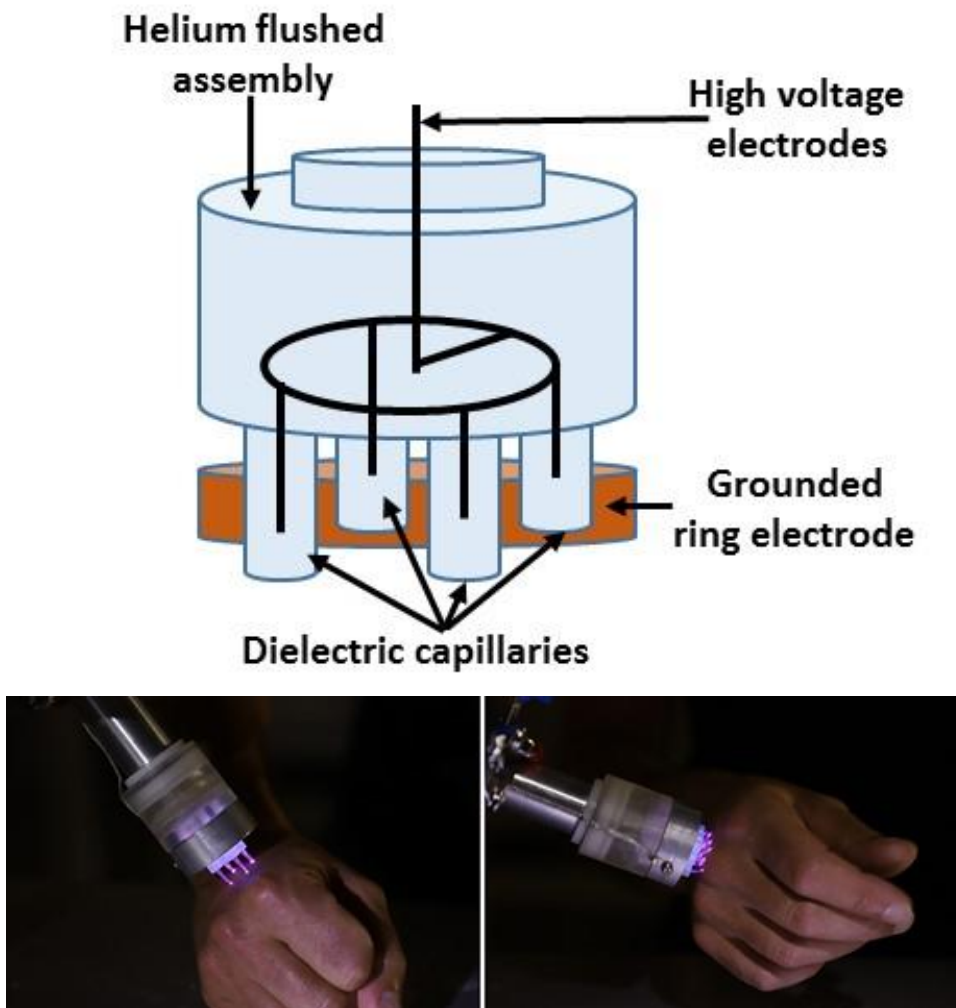

Figure 2 Top: schematic of the low voltage multi-jet applicator (option 3). Bottom: 4 and 9 low voltage multi-jets delivered on the author's hand. Parameters: voltage $2.5 \mathrm{kV}$, repetition rate $20 \mathrm{kHz}$, gas flow $2 \mathrm{~L} / \mathrm{min}$.

The table 1 summarizes the main characteristics for the three plasma device options discussed in this section.

\begin{tabular}{|c|c|c|c|c|}
\hline & $\begin{array}{l}1^{\text {st }} \text { option } \\
\text { Single jet }\end{array}$ & \multicolumn{2}{|c|}{$\begin{array}{l}2^{\text {nd }} \text { option } \\
\text { multi-jets from one primary jet }\end{array}$} & $\begin{array}{l}3^{\text {rd }} \text { option } \\
\text { bunch of } \\
\text { individual jets }\end{array}$ \\
\hline Voltage (kV) & $10-20$ & \multicolumn{2}{|c|}{14} & 3 \\
\hline $\begin{array}{l}\text { Repetition } \\
\text { rate }(\mathbf{k H z})\end{array}$ & 20 & \multicolumn{2}{|l|}{2} & $10-20$ \\
\hline $\begin{array}{l}\text { Gas flow } \\
\text { (L/min) }\end{array}$ & 0.5 & \multicolumn{2}{|l|}{4} & 3 \\
\hline $\begin{array}{c}\text { Key } \\
\text { advantage } \\
\end{array}$ & $\begin{array}{l}\text { Simplest } \\
\text { design }\end{array}$ & \multicolumn{2}{|c|}{ Large surface treatment } & $\begin{array}{l}\text { Less sensitive to } \\
\text { target distance } \\
\text { topology }\end{array}$ \\
\hline $\begin{array}{c}\text { Name of the } \\
\text { plasma } \\
\text { applicator }\end{array}$ & Single jet & Multi spot & Diffuse mode & Low voltage \\
\hline $\begin{array}{l}\text { Plasma } \\
\text { impact } \\
\text { on target }\end{array}$ & $\begin{array}{l}\text { One two mm } \\
\text { spot moving } \\
\text { over a } 2 \mathrm{~cm}^{2} \\
\text { disk }\end{array}$ & $\begin{array}{c}4+12+12+24, \text { one } \\
\text { mm spots } \\
\text { distributed over } \\
8 / 18 / 28 / 38 \mathrm{~mm} \text { in } \\
\text { diameter rings }\end{array}$ & $\begin{array}{l}\text { Same as for } \\
\text { multi spot with } \\
\text { additional } \\
\text { diffuse volume } \\
\text { between the } \\
\text { multi jets }\end{array}$ & $\begin{array}{l}\text { 4/9/13 two } \mathrm{mm} \\
\text { spots distributed } \\
\text { over a } 2 / 3 / 3 \mathrm{~cm} \\
\text { in diameter disk }\end{array}$ \\
\hline
\end{tabular}

Table 1 Main characteristics of the plasma gun based devices 
As shown in figure 3, a membrane filtration system composed of a funnel and a vacuum valve was used to prepare samples with different bacterial strains. The bacterial inoculum solution was set in the funnel, the base of which was equipped with a membrane $47 \mathrm{~mm}$ in diameter and having a porosity of $0,45 \mu \mathrm{m}$. This membrane, set on a filter stone, acted as filter for the inoculum when the vacuum pump was switched on. In this work, an inoculum $\left(10^{3} \mathrm{CFU} / \mathrm{ml}\right)$ volume of $100 \mathrm{ml}$ was filtered across the membrane. The membrane was then set on an agar disk (50 $\mathrm{mm}$ in diameter) prepared in a petri dish. Following a 24-hour incubation period at $37^{\circ} \mathrm{C}$, a $10 \mathrm{~cm}^{2}$ bacterial lawn was produced as shown in figure $3 \mathrm{~d}$.

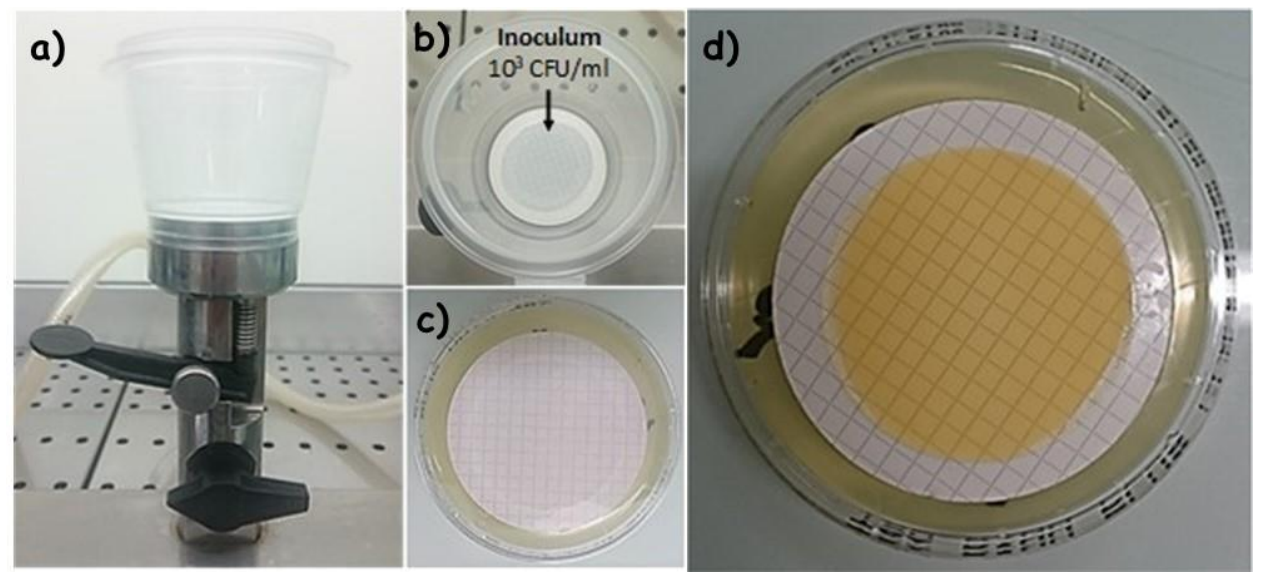

Figure 3 a) Funnel and valve connected to a vacuum pump (not shown) used to initiate the bacteria inoculum preparation, b) Top view of funnel, whose base is covered with a membrane used to filter the bacterial inoculum, c) zoom on the membrane set on agar prepared in a petri dish right at the end of the filtering process, d) view of the grown bacterial lawn following a 24 -hour incubation at $37^{\circ} \mathrm{C}$.

Otherwise mentioned in the results section, the plasma treatments were performed right after the inoculated membrane was set on the agar substrate, i.e. before the 24-hour incubation period, meaning before the growth of the bacterial lawn.

The plasma treatments consist in 1, 5 or 10-minute exposure with a gap distance between multi-jet bottom base and the membrane of $5 \mathrm{~mm}$, a gas flow rate of $4 \mathrm{~L} / \mathrm{min}$, peak voltage amplitude of $14 \mathrm{kV}$ and pulse repetition rate of $2 \mathrm{kHz}$ (both multi-spot and diffuse mode applicators were used). All experiments have been performed in triplicate. Control samples consisted in gas flow only exposure of the membrane on agar substrates for the same durations (1 to 10 minutes) but with no plasma ignition.

Larger surface bacterial lawn of $12 \times 12 \mathrm{~cm}^{2}$ inoculated with patients collected resistant bacteria have also been prepared and exposed to plasma. A $100 \mu$ l volume of bacterial solution having $10^{4}$ colony forming unit per milliliter $(\mathrm{CFU} / \mathrm{ml})$ was spread over the surface of the agar plate. These large surface inoculated agar samples were then incubated at $37^{\circ} \mathrm{C}$ for 24 hours with or without preliminary plasma treatment. The plasma treatment with the multi spot applicator was performed in a scanning protocol with the help of a programmable displacement board allowing various scanning patterns and speeds with the fixed plasma applicator and the moving agar sample as shown in figure 4 . 


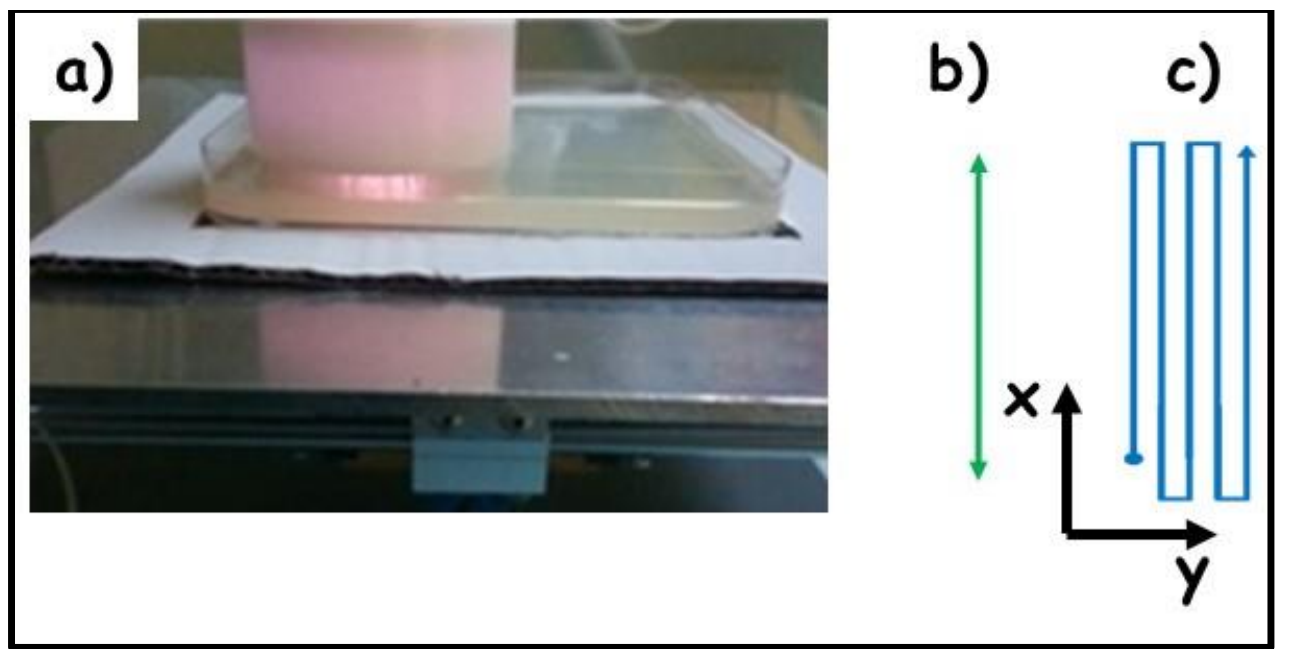

Figure 4 a) Multi jets treatment of large surface inoculated agar samples set on a programmable displacement board, b) translation scanning pattern, c) zigzag scanning pattern.

Two scanning patterns have been experienced. First a translation pattern with back and forth linear displacements, the back and forth duration being of 12 seconds and having an extension of $100 \mathrm{~mm}$. This translation pattern was repeated respectively 5,25 or 50 times thus corresponding to a whole plasma treatment duration of 1,5 and 10 minutes. The second pattern, zigzag-like, is shown in figure $4 c$, and combined translation along the $x$ and $y$ axis of 100 and $2 \mathrm{~mm}$, respectively. The time set to process the full pattern was one-minute long and this was repeated for 5 or 10 times, corresponding to 5 or 10 -minute plasma exposure durations.

\subsubsection{Bacterial strains}

Two class of bacterial strains have been used in this work. First freeze-dried strains, Staphylococcus aureus subsp. aureus ATCC®9144TM and Pseudomonas aeruginosa ATCC®9027TM respectively cultured on ATCC® Medium 18: Trypticase Soy Agar (TSA) and ATCC® Medium 3: Nutrient agar (supplied by Institut Pasteur). These two non-resistant bacteria were inoculated on agar substrates from solutions having a $10^{3} \mathrm{CFU} / \mathrm{ml}$ concentration. Second, three resistant strains were isolated from wound samples collected from patients suffering from chronic wounds, namely S. aureus, P. aeruginosa and E. coli. The individual strain selection was achieved by culturing these patient's samples on various selective agars. These resistant bacteria were then inoculated on TSA substrates from solutions having a $10^{4} \mathrm{CFU} / \mathrm{mL}$ concentration. The experiment with the combination of these three resistant bacteria, documented in section 3.4, was performed from mixing the three bacterial solutions prepared with a $10^{4} \mathrm{CFU} / \mathrm{ml}$ concentration of each bacteria. The resistance of each resistant bacteria strain was qualified through antibiogram analysis with the inclusion of nine different antibiotic drugs. The most resistant strain was measured to be the $P$. aeruginosa being only partly sensitive to one aminoglycoside drug. This strain was selected to illustrate the potent bactericidal action of multi jets one resistant pathogen as documented in section 3.3.

All the decontamination experiments were performed in the microbiology hygiene laboratory from the Orleans Regional Hospital under the supervision of Dr M. Demasure.

\subsubsection{Agar samples for multi-jets characterization}

Agarose gel samples were prepared by dissolving $1.5 \mathrm{mg} \mathrm{ml}^{-1}$ agarose of microbiology powder in a physiological saline solution $(\mathrm{NaCl} 150 \mathrm{mM})$. The solution was heated on a conventional heating magnetic stirrer until all the powder was dissolved. Agarose mix was poured to obtain gels of $2 \mathrm{~mm}$ thickness. The gels were stored at $4^{\circ} \mathrm{C}$ for $12 \mathrm{~h}$ 
before use. KI-starch-loaded agarose samples were used to evaluate the spatial distribution of generated reactive species. The samples were prepared by dissolving $1.5 \%$ agarose of microbiology powder, $0.3 \% \mathrm{KI}$ and $0.5 \%$ starch $\left(\mathrm{C}_{6} \mathrm{H}_{10} \mathrm{O}_{5}\right)_{\mathrm{n}}$ in a saline physiological solution $(\mathrm{NaCl} 150 \mathrm{mM})$.

\subsection{Current measurement}

Current measurements for multi-jets impinging on a grounded metallic plate documented in section 3.1 were performed by measuring the voltage drop across a carbon resistor connected in series with the plate. The signals were recorded using a Tektronix 500 $\mathrm{MHz}$ probe (TPP0500B) $500 \mathrm{MHz}$ bandwidth and a $500 \mathrm{MHz}$ bandwidth digital oscilloscope Tektronix MDO3054.

\section{Results}

\subsection{Multi-jets characterization}

The power coupled to, and the current flowing across each individual 52 secondary jets with the multi spot applicator were not measured in this work, but it is speculated that they are more or less evenly distributed in between each of these secondary jets. Indeed, while not specifically assessed in this work, the longtime exposure up to 5 to 10 minutes of agar sample never reveal any local melting, ablation or deformation of the sample at the position of the plasma spots or in the zone in between them. This is an indication that neither severe temperature increase nor dramatic ion bombardment occur during multi-jets exposure. Nevertheless, figure 5 reveals that the secondary jets generated from the two inner rings of the multi spot plasma applicator exhibit a higher visible light intensity. A first reason for this lies in the secondary jets mechanisms. Indeed, the secondary jets are generated after that the primary jet ignited in the upper section of the applicator splits in the first channels distributed along the first inner ring $[45,46]$. Then a second splitting of the remaining ionization wave propagating in the upper section from the first to the second ring, occurs and generates the secondary jets emerging from the second ring channels. Same process repeats for the third and fourth series of multi-jets emerging from the periphery of the applicator. During these splitting processes, part of the power is carried by the secondary jets, the rest being transported in the plasma developing in the upper part of the applicator before next splits occur in the large diameter ring. A second likely reason for this higher intensity of the inner secondary jets is that even if the upper section was empirically designed to allow for a homogenous gas flow distribution in the channels where secondary jets are generated, it is suspected that this gas flow is anyway lower is the peripheral holes.

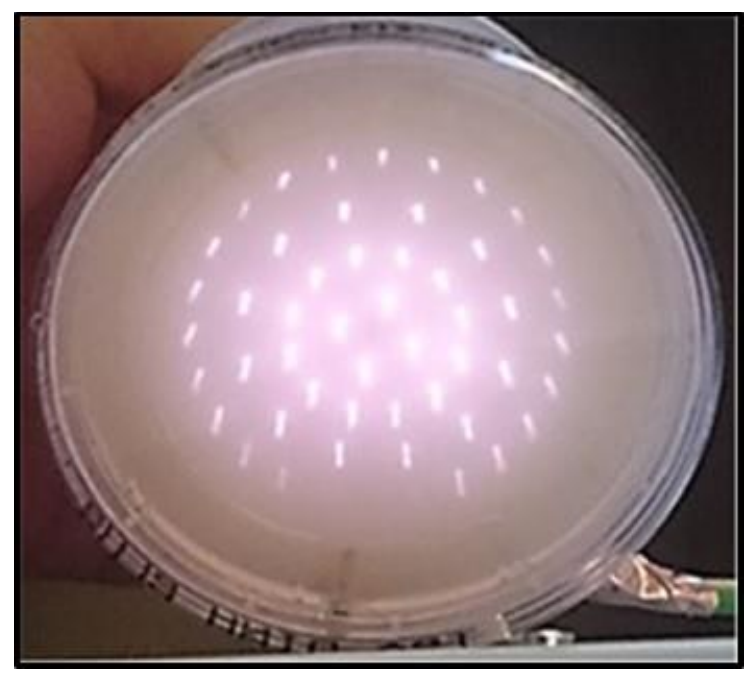

Figure 5 Photograph of the multi spot plasma applicator delivering the secondary multi-jets in ambient air 

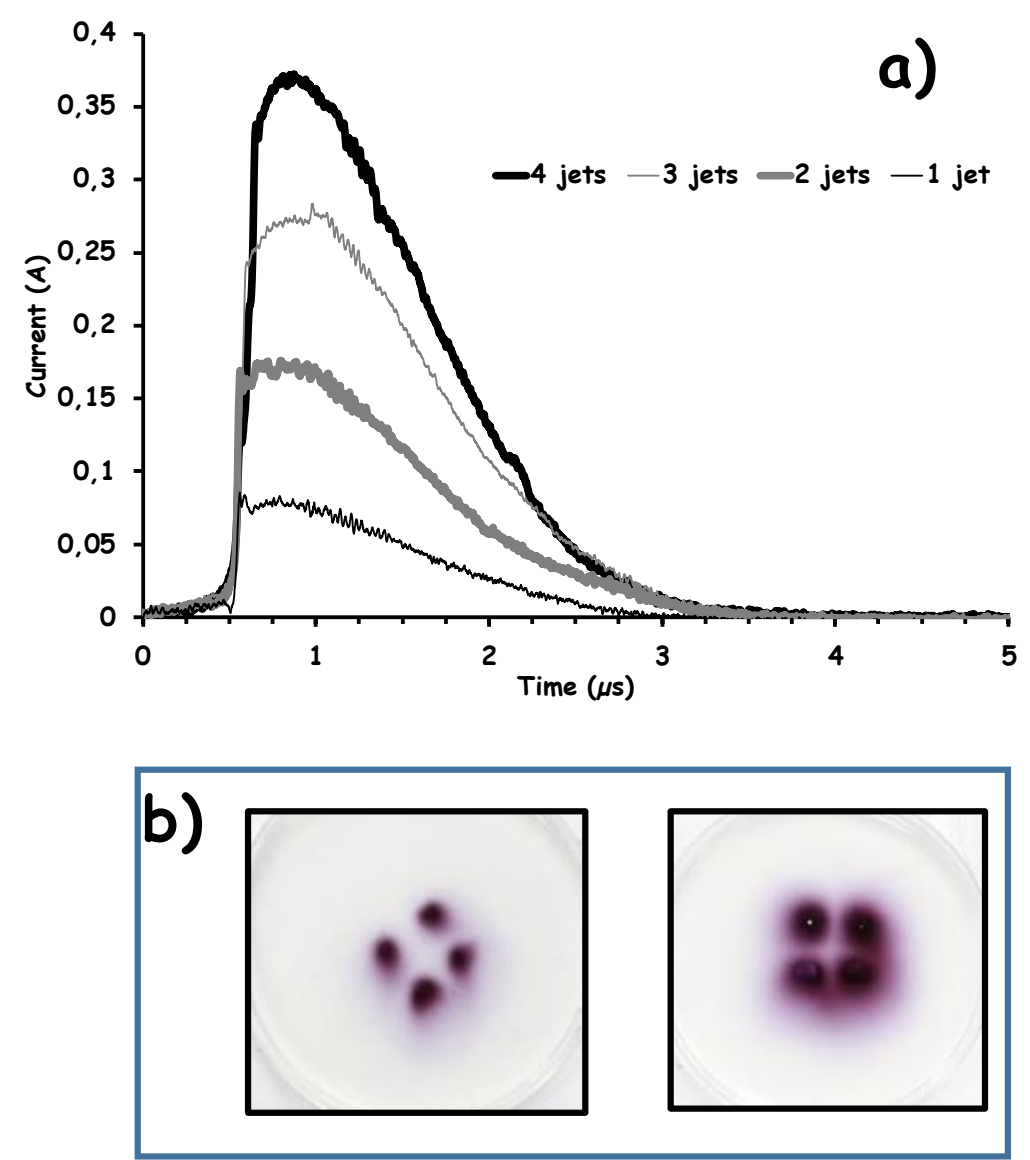

Figure 6 a) Current delivered on a metallic target with 4 jets: bold black trace, 3 jets thin grey trace, 2 jets: bold grey trace and 1 jet: thin black trace, b) image of KI-enriched agar samples exposed to four multi-jets generated with the low voltage applicator during left: $60 \mathrm{~s}$ and right: $240 \mathrm{~s}$.

Figure 6a presents the current measurements performed with the use of a grounded metallic target set $10 \mathrm{~mm}$ away from the low voltage applicator delivering 4 secondary jets. By using a dielectric foil set to impede either no, one, two, and three of the secondary jet to impact the target, the figure $6 \mathrm{~b}$ demonstrates that each one the secondary jets carry on fourth of the whole current measured when the four jets impinge on target.

The figure $6 \mathrm{~b}$ illustrates the operation of this four multi-jet device exposing agar sample [49] enriched with potassium iodide. The potassium iodide is used as an indicator for the delivery of reactive species by the multi-jets $[44,50]$. Is it shown that for a $60 \mathrm{~s}$ plasma exposure, the reactive species are delivered as four spots on the sample while for a longer exposure of $240 \mathrm{~s}$, the reactive species are detected almost all over a disk defined by the edges of the four multi-jets assembly. Same results were achieved for applicators generating 9 and 13 secondary jets distributed over a disk of $50 \mathrm{~mm}$ in diameter.

\subsection{Inactivation of Staphylococcus aureus}

The figure 7 presents the multi spot plasma treatment of $S$. aureus inoculated membrane set on agar substrates, in various experimental conditions. 


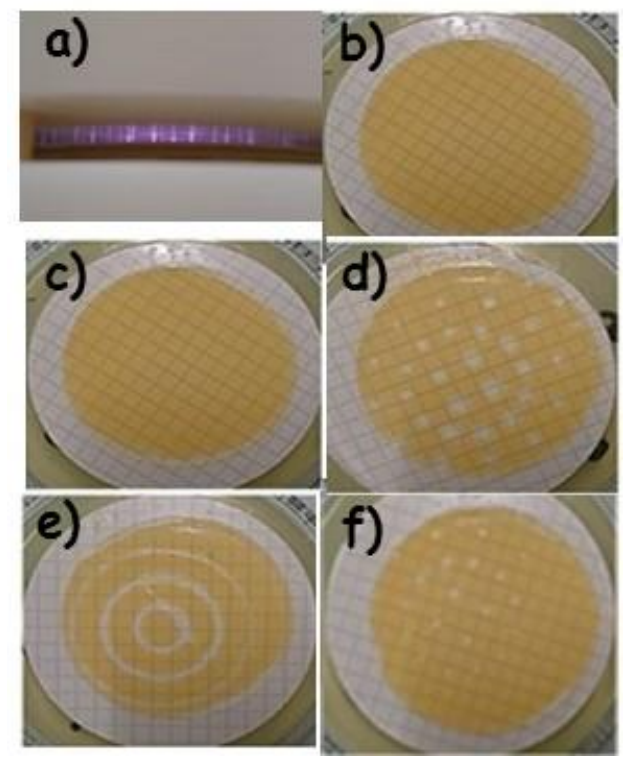

Figure 7 Inactivation of $S$. aureus with the multi spot plasma applicator. a) Multi spot plasma treatment of inoculated membrane on agar substrate, b) H24 image of the untreated sample, c) H24 image of the sample exposed at $\mathrm{H} 0$ to 5 min helium flow, d) H24 image of the sample exposed at $\mathrm{H} 0$ to 5 min plasma treatment in static mode, e) $\mathrm{H} 24$ image of the sample exposed at $\mathrm{H} 0$ to $5 \mathrm{~min}$ plasma treatment with a $1 \mathrm{rpm}$ rotation, f) $\mathrm{H} 24$ image of the sample exposed at $\mathrm{H} 0$ to 1-minute plasma treatment in static mode. H0 and H24 stand for hour zero as the time origin and 24 hours later, respectively.

As expected, the control gas treatment shows no bactericidal action, as shown in figure $7 \mathrm{c}$ where the bacterial lawn full development is observed in the same manner as for the untreated sample in figure $7 \mathrm{~b}$. This confirms the helium gas flow has no impact on the inoculated membrane, inducing no drying or spray action, as the 24-hour incubation results in the same growth of the bacterial lawn as for untreated treated sample. In figure $7 \mathrm{~d}$, it is observed that the impact of the respectively 4,12 and 12 secondary jets -distributed from the center to the periphery of the plasma applicator- results in a full inactivation of the bacteria. Because of an imperfect centering of the plasma applicator with respect to the sample, only 4 secondary jets distributed along the $38 \mathrm{~mm}$ in diameter outer ring of the multi spot applicator impacted the bacterial lawn, which was about $40 \mathrm{~mm}$ in diameter. This is visible in the top right region of figure $7 \mathrm{~d}$. Indeed 24 hours after multi jet treatment, the bacterial lawn growth is fully inhibited at the positions of these 32 plasma jet impact. This first indicates that the plasma action is localized in the region where plasma jets impacts and do not induce any strong effect in between the secondary jets regions during plasma jet exposure but after the following 24-hour incubation as well. The ratio of the sum of these 4,12,12 and 4 plasma spot impact surfaces over the bacterial lawn surface results in about an $8 \%$ coverage for a 5 -minute-long static exposure with the multi spot applicator. Thus, the decontamination of the full surface for the extended bacterial lawn would require a displacement of the plasma applicator, as will be documented in section 3.4. One observes that the higher intensity of the central multi-jets, as discussed from the figure 1, results in larger inactivation spots as compared to the much peripheral multi-jets effect. As the visible diameters of all the secondary jets is about constant, this means that the plasma light emission cross section observed on the sample surface is not the best indicator to predict the inhibition zone diameter. Both plasma generated reactive species and transient electric fields inherent with the multi-jets delivery may have an effect away from the plasma emitting light volume.

Figure 7e indicates that $5 \mathrm{~min}$ treatment with the sample rotation (rotation speed was of 1 revolution/min) is enough to prevent bacterial lawn development at the plasma jet impact positions. This means that plasma exposures shorter than 5 minutes are sufficient to inactivate $S$. aureus. One also notes that the inactivation is more efficient along the two 
inner circles where 4 and 12 multi-jets, respectively, are distributed, than for the third and fourth larger diameters circles exposed with the 12 and 24 multi-jets, respectively, ignited out of the channels from the two outer rings of the applicator. Two main reasons may be invoked to explain this observation: first as discussed from the figure 5, the multi jets on the center are more intense, and second for a constant rotation speed of the sample, the plasma exposure duration per surface unit is obviously shorter for the larger diameter circles. The key role of the treatment time on the inhibition zone size is confirmed in figure $7 \mathrm{f}$, where a one-minute multi-jet exposure was processed in a static mode, i.e. without sample rotation. This short exposure is enough to inactivate the bacteria but the inhibition spots are much smaller and correlates with the $5 \mathrm{~min}$ and rotating sample observations in figure 6e along the two larger diameter inhibition circles.

The use of the multi spot plasma exposure protocol including the rotation of the sample, demonstrates that the increase of the number of secondary jets for larger diameters is convenient to expand the plasma applicator action on large surface and that scanning of the sample at moderate speed is efficient as will be confirmed in section 3.4. The optimal protocol results from the balance between the goal to set a high scanning speed to allow for multi pass over the sample during a short plasma treatment duration and the limitation imposed by the necessity to prevent too strong helium gas flow disturbance at the outlets of the channels of the applicator. This latter point depends on the helium gas flowrate and the design (length and diameters) of the channels.

Another strategy assessed in this work, was to generate multi-jets in a more heliumrich volume to try to achieve a more diffuse and larger volume plasma discharge at the surface of the sample. The figure 8a presents the diffuse mode plasma treatment of $S$. aureus inoculated membrane set on agar substrates, in various experimental conditions.

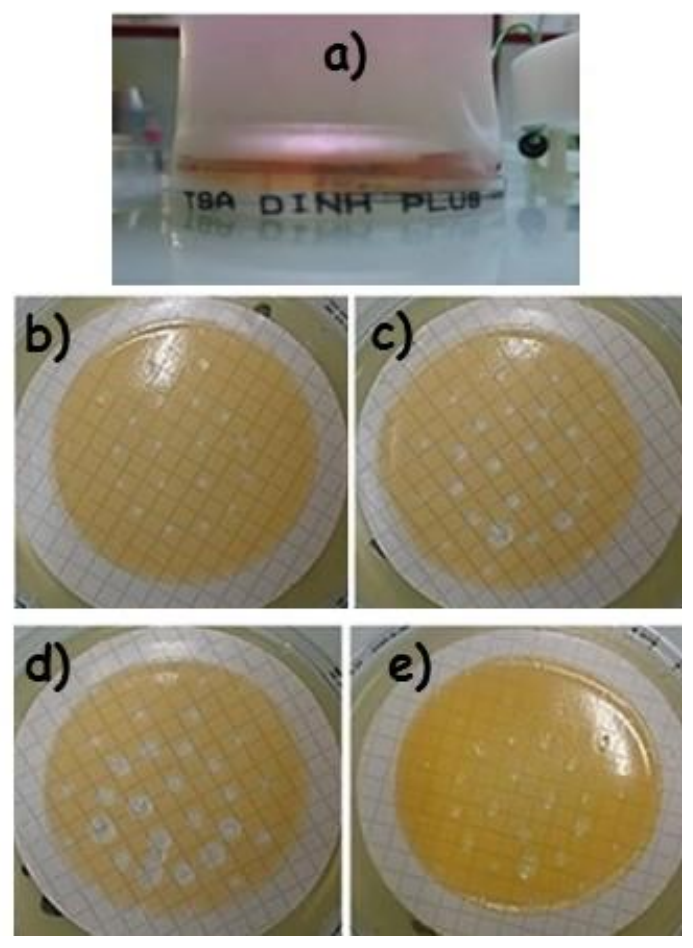

Figure 8 Inactivation of S. aureus with the diffuse mode plasma applicator. a) Diffuse mode plasma treatment of inoculated membrane on agar substrate, H24 images of the sample exposed at $\mathrm{H} 0$ to 1 (b), 5 (c) and 10 (d) minute plasma treatment, e) $\mathrm{H} 24+10$ minutes image of the sample exposed at $\mathrm{H} 24$ to 10 min plasma treatment. $\mathrm{H} 0$ and $\mathrm{H} 24$ stand hour zero as the time origin and 24 hours later, respectively.

Figures $8 \mathrm{~b}, \mathrm{c}$, d present the bacteria inactivation for 1, 5 and 10-minute exposures in static mode with the diffuse mode applicator. Three main observations can be done. 
First, the inhibition diameter is time exposure-dependent, indicating that the inactivation is not only the result of the direct impact of the plasma on the sample but that the plasma-induced effect includes either some diffusion mechanism or bystander processes previously speculated for plasma cancer treatment experiment analysis [51,52]. In this work, the results discussed from figure 6 showing that the reactive species delivery in agar sample was plasma exposure duration dependent tend to support that the inhibition zone diameter increase is likely due to the diffusion of the reactive species. Nevertheless, as during plasma jet exposure, the bacteria are also submitted to intense transient electric field during each voltage pulse, it may be suspected that the accumulation of these electric field stimulation in combination with the delivery of reactive species may play a role in the gradual spread on the inhibition zone. Indeed, the electric field driven by the space charge at the tip of the ionization wave front, such as developing for $\mathrm{kHz}$ plasma jets, combines a longitudinal and a radial component, the latter exhibiting a decaying intensity versus the distance from the plasma jet axis [45, 53-57]. With our experimental set-up, and with a slightly higher peak voltage amplitude applied to the plasma reactor $16 \mathrm{kV}$ instead of $14 \mathrm{kV}$ in this work, electric field with amplitudes ranging from 3 to $8 \mathrm{kV} / \mathrm{cm}$ were reported along the plasma jet inside the capillary [45], while amplitude as high as $45 \mathrm{kV} / \mathrm{cm}$ were measured at the tip of the plasma plume [55]. One may suspect that besides the reactive species delivery and action on bacteria, the bacteria on the central zone of the plasma jet impact zone will rapidly be inactivated as there the electric field strength is large enough, while those on the more outer locations will require the accumulation of a larger number of electric field pulses of lower strength. Such combinatory and thresholddependent action of pulsed electric field with reactive species was recently reported [48, 58-61] during plasma treatment of various cell lines.

Second, the inhibition diameters are no longer larger for the 4 central multi-jets but for the 12 second multi-jets distributed on the $18 \mathrm{~mm}$ in diameter ring, conversely to the results obtained with the multi spot applicator in figure 7 .

Third, the yellow color, representative for the $S$. aureus colonization, is less intense in between the multi-jet impact regions in figure 8 than it was in figure 7 . This indicates that the growth of bacterial lawn even in the region in between the multi spots is reduced with the diffuse mode applicator, presumably because of reactive species' diffusion from impact plasma points thanks to additional sleeve.

These two latter observations reveal that the diffuse mode applicator modify the relative bactericidal efficiency of the individual multi-jets and that the whole surface of the sample is plasma-treated and partly inactivated even though the multi-jets are much more effective than the diffuse plasma.

In the context of wound treatment, the delivery of plasma can be planned for two different scenarios. The first would be to prevent either bacteria colonization right after the wound occurrence or bacteria re-colonization following a disinfecting care of a persisting wound. This was the motivation of the previous documented results in figures 7 and 8 where the plasma delivery was performed right after the bacteria inoculation on the agar sample. The second and most critical need for alternative treatment, likely plasmabased, is for infected or chronic wound situation where the bacterial colonization is already achieved. To assess the potential action of plasma multi-jets for this second scenario, the figure 8e presents the 10-minute-long treatment performed on a mature bacterial lawn, obtained after a 24 hours' incubation of the inoculated membrane on the agar substrate. It is observed that the diffuse mode applicator induces some bactericidal effect on the mature bacterial lawn. Partly inhibited multi spots are observed together with a slightly less yellow colored lawn in the center than in the peripheral regions of the sample.

3.3 Inactivation of Pseudomonas aeruginosa ATCC®9027TM and resistant Pseudomonas aeruginosa cultured from patient's sampling 
The figure 9 presents treatment time dependence with the diffuse mode plasma applicator for the $P$. aeruginosa ATCC@9027TM and resistant $P$. aeruginosa inoculated membrane set on agar substrates.

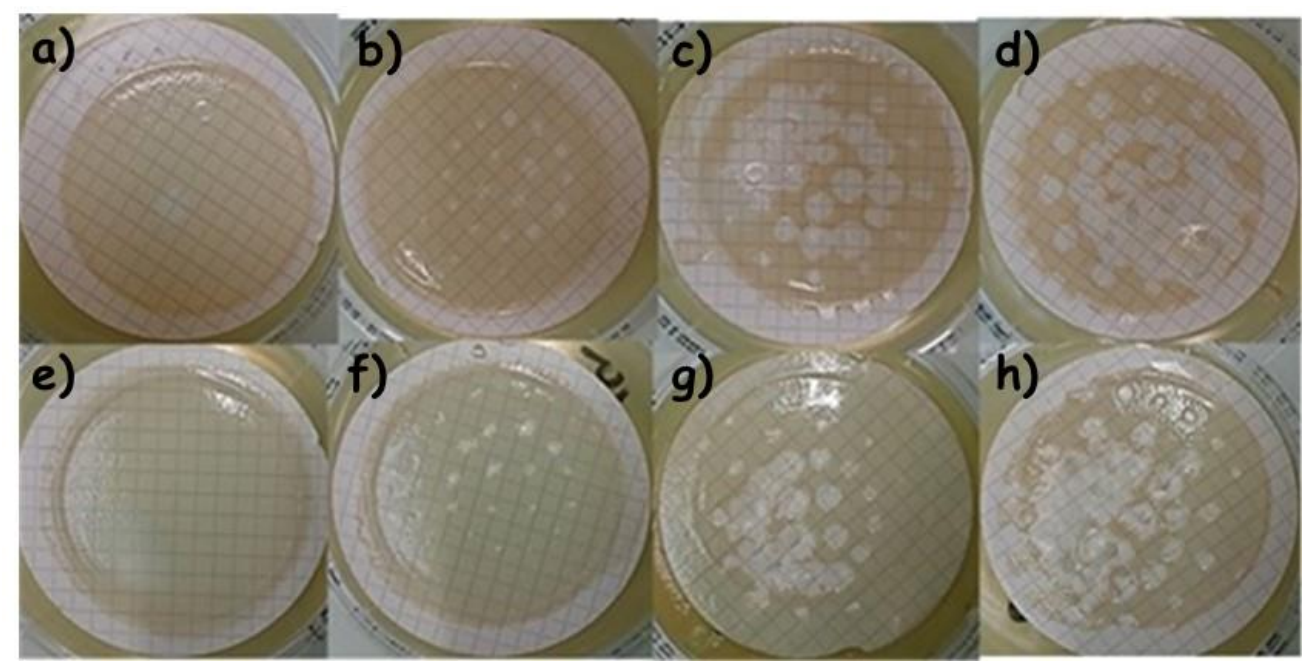

Figure 9 Inactivation of $P$. aeruginosa ATCC®9027TM and of resistant $P$. aeruginosa with the diffuse mode plasma applicator. H24 images of the $P$. aeruginosa ATCC®9027TM inoculated sample exposed at $\mathrm{H} 0$ to 0 (a), 1(b), 5 (c) and 10 (d) minute plasma treatment and of resistant $P$. aeruginosa inoculated sample exposed at $\mathrm{H} 0$ to 0 (e), 1(f), 5 (g) and 10 (h) minute plasma treatment.

As obtained with the $S$. aureus in figure 8 , the use of the diffuse mode applicator for 1,5 and 10 minutes results in the inactivation of the two $P$. aeruginosa strains. It is again observed that the inactivation spot diameter, associated with each single jet, increases with the treatment duration, and that the bacteria lawn growth is also reduced in the region in between these spots, where the diffuse plasma is active. Two main additional remarks can be addressed. First, it is quantitatively shown that the multi-jets based treatment is more efficient for the two $P$. aeruginosa strains than for the $S$. aureus. Second, it is noticeable that the multi-jet based treatment is as efficient for the regular and the resistant strain, clearly differencing the plasma action from other conventional strategies based on antibiotics supply. This was the main objective of this work to assess a new bactericidal agent in the perspectives of the development of innovative disinfecting process for situation were no therapeutic protocol is today available, as unfortunately more and more encountered with nosocomial infections.

\subsection{Large surface resistant bacterial lawn inactivation with scanning protocols}

The figure 10 presents the multi spot plasma treatment of resistant $P$. aeruginosa, $S$. aureus and E. coli inoculated agar substrate, the three strains being collected from patients suffering from chronic wounds. The translation scanning mode was processed for 1, 5 and 10 minutes in different regions of the agar plate. 

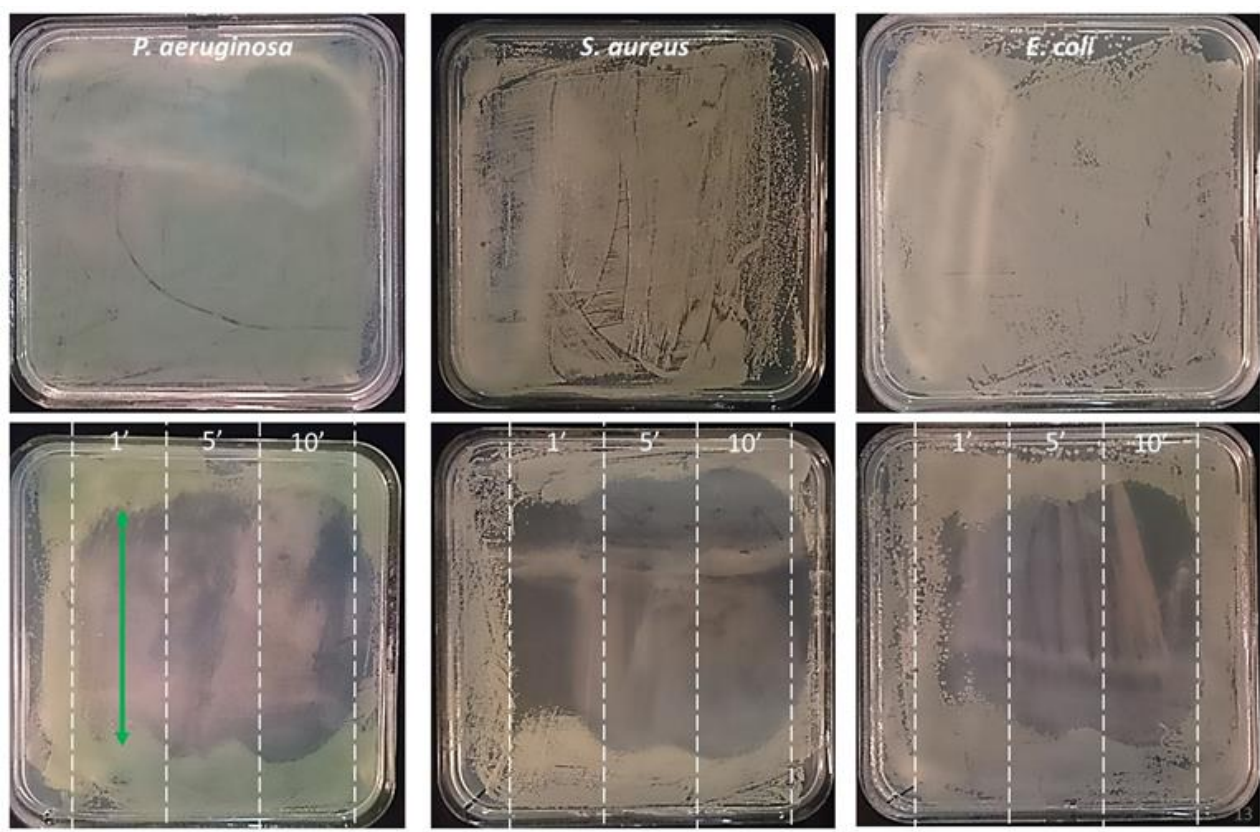

Figure 10 Inactivation of large surface resistant bacterial lawn with the multi spot plasma applicator with the translation scanning mode. On top, images of resistant $P$. aeruginosa (left), S. aureus (middle) and E. coli (right) the 24 hours after their inoculation. In the bottom, H24 images of the P. aeruginosa (left), S. aureus (middle) and E. coli (right) inoculated sample exposed at $\mathrm{H} 0$ to 1, 5 and 10-minute plasma treatment as indicated between the vertical dashed lines. The size of each treated zone is about $40 \mathrm{~cm}^{2}$.

There may be some overlap of the treatment in one zone (for 1, 5 and 10 minutes' plasma exposure) with the neighbored zones. Because of this possible artifact, the decontamination action is discussed for the central band of each of the three different treatment duration zones. For each of the three strains, the multi spot scanning protocol results in a time-dependent inactivation efficiency. Nevertheless, even for the shortest, one-minute treatment time, the bacterial lawn growth is almost already fully and homogenously inhibited. It is observed that the $P$. aeruginosa, $S$. aureus present a higher sensitivity than $E$. coli to the plasma treatment. Figure 10 presents the images of the bacterial lawn after the plasma treatment and a 24-hours incubation period, but it was also verified that even after an incubation period as long as seven days, the bacterial lawn growth was still completely inhibited.

In the perspective of patient's wound plasma treatment it is important to assess the bactericidal action of plasma jets not only on a single strain inoculum but also for a mixture of different strains, as wound are most of the time colonized by a symbiotically living bacteria assembly. The figure 11 presents the multi spot plasma treatment of a combination of resistant $P$. aeruginosa, $S$. aureus and $E$. coli inoculum spread over an agar substrate. The zigzag scanning mode was processed for 1, 5 and 10 minutes in one selected region of the agar plate. This scanning mode was selected to mimic the way medical doctors or nurses may treat a large wound with a plasma device. 


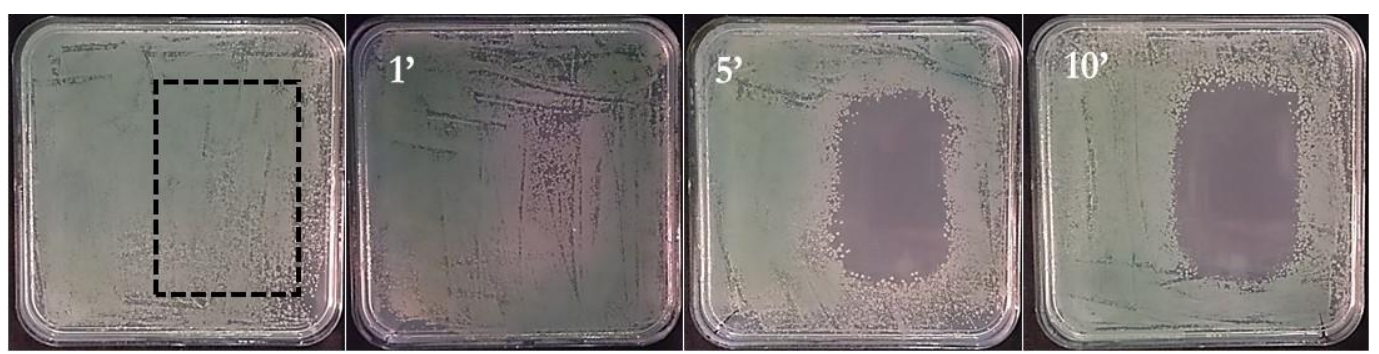

Figure 11 Inactivation of large surface bacterial lawn composed of a mixture of three resistant strains with the multi spot plasma applicator applied in the zigzag scanning mode. H24 images of the inoculated sample exposed at H0 to 1, 5 and 10-minute plasma treatment. The dashed rectangle zone indicates the plasma treated region. The size of the treated zone is about $32 \mathrm{~cm}^{2}$.

It is observed that after a one-minute plasma treatment, the $P$. aeruginosa inactivation is already achieved as the green color, indicative of this bacteria colonization following a 24-hour incubation, has vanished. A 5-minute long treatment leads to the full inactivation of the three bacteria strains in the scanned region, while some circle shaped colonies are observed on the edges of the treated zone. These circle shape colonies are likely to be assigned to E. coli persistence, as this specific morphology was already observed in the single bacteria inoculation experiment documented in figure 10. A 10-minute plasma treatment leads to the full inactivation of the bacterial inoculum with no evidence for any of the three bacterial strains growth. The plasma treatment of the mixed inoculum reveals that this inactivation method is likely to be efficient for the decontamination of multi infected wounds. Finally, full decontamination was also achieved for S. dysgalactiae and B. subtilis strains collected at Orleans Hospital (data not shown).

\subsection{Pilot tolerance study on the use of plasma therapy for wound treatment}

This preliminary study was performed at Orleans Regional Hospital (CHRO) in the department of Tropical and Infectious Diseases under the supervision of Dr T. Prazuck. The study was approved by the CHRO ethical committee on the base of bibliographic data published by different teams reporting clinical trials with non-thermal plasma devices and following a tolerance study performed at Institut Gustave Roussy (Villejuif, France) under the supervision of Dr L. Mir [62], with the multi-jet applicator technology described in this work applied to both nude and hairy mice. It was measured that neither severe nor irreversible skin disorders were induced following minutes long multi-jet delivery in a single fraction. The tolerance study performed at CHRO included five hospitalized patients, bearing superinfected wounds having diameters ranging from 3 to $15 \mathrm{~cm}$. A single jet low voltage device was used to deliver plasma during one minute for each half square centimeter surface unit, as shown in figure 12 . The full time exposure of the wound treated zone, which was not always covering the whole ulcerated tissue, ranges from 15 to 30 minutes. The plasma device was handheld and operated either by the coauthors or the medical staff of the hospital. Each of the five patients was plasma treated either daily or each other day, reaching at the end a median 5 day fractions of plasma treatment. The patients were preventively grounded by means of an antistatic bracelet so to better control their potential and the plasma treatment. Tolerance was assessed by scoring the patient feelings during and after the plasma delivery fractions. It was also systematically and carefully investigated by nurses in charge of the treatment that no necrotic, inflammatory and cutaneous stress appeared at the place where plasma jet was applied. As reported in Figure 12, the temperature of the treated area was monitored live by means of an infrared camera (Fluke Ti480 by Fluke). The surface of the wound results in general colder due to the presence of liquid and the consequent cooling caused by evaporation. At the place where the plasma jet was applied a temporary small increase (about $+3-5^{\circ} \mathrm{C}$ ) of the surface temperature was observed. The recorded temperature remained always below $40{ }^{\circ} \mathrm{C}$ so adverse effect due to excessive heating can be discarded. 


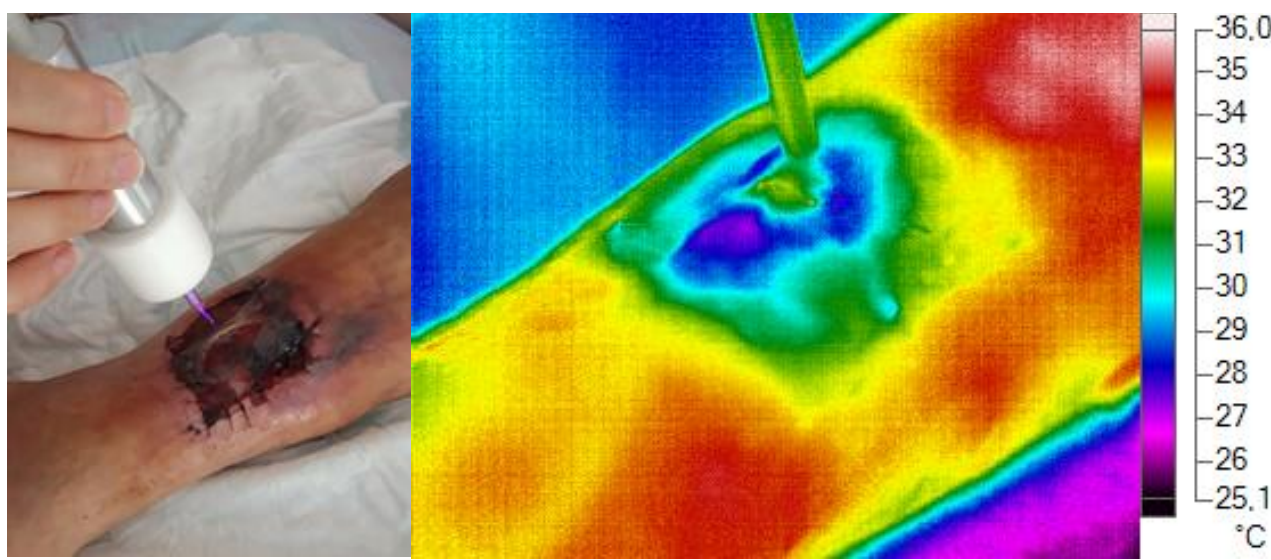

Figure 12 Photo of the delivery of a single jet generated with the low voltage applicator on a patient's wound included in the pilot tolerance study performed at CHRO, (right) the treatment monitored by means of an IR camera.

The tolerance study was overall scored as excellent. The scoring, associated with any local or systemic pain feeling during or after plasma fraction, keeps at the same value as that expressed before plasma treatment for each of the patient or for all of the plasma fractions. This testify the absence of pain, burn or unpleasant feeling by the patient during the plasma delivery on injured skin. No inflammation, necrosis or degradation of the ulcerated tissue were reported.

The figure 13 presents the Staphylococcus aureus ATCC9144 and Pseudomonas aeruginosa ATCC9027 colony reduction versus the plasma exposure duration. For the two bacteria, three different initial concentrations were exposed in triplicate: respectively about 170, 90 and 50 and 160, 55, 30 colonies/membrane were used for Staphylococcus aureus and Pseudomonas aeruginosa respectively. These colony concentrations were selected as being representative or typical infection level in the hospital context following the baseline decontamination protocols using disinfectant. In figure13, the colony reduction was plotted after applying a normalization of for three experiments for each of the bacterial strain. One note that whatever the initial colony concentration, the same trends are measured, leading to an efficient reduction after a 10-minute-long exposure for both bacterial strains.

a)

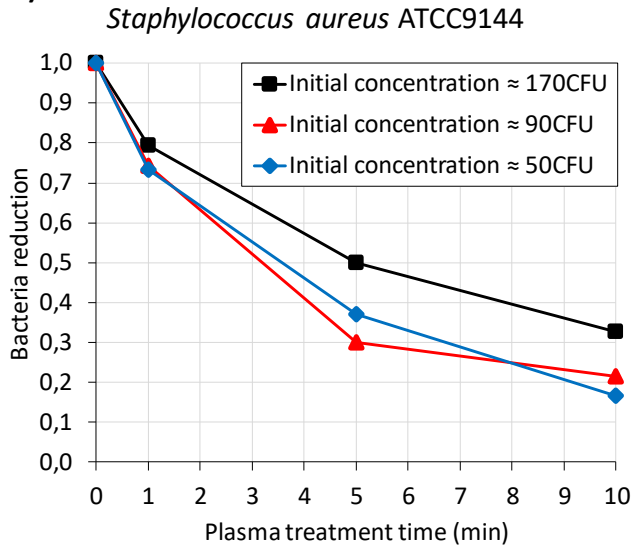

b)

Pseudomonas aeruginosa ATCC9027

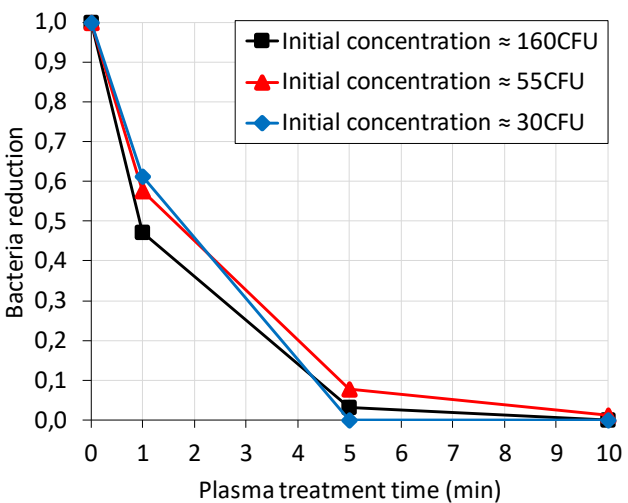

\section{Discussion}


This work reports on the design and operation of multi jets devices based on the plasma gun technology [42,43].

The first device developed as a "multi spot plasma applicator" and a slightly modified derived version labeled as "diffuse mode plasma applicator" allows to deliver 52 millimeter-sized helium jets in ambient air at a pulse repetition rate of $2 \mathrm{kHz}$. In the diffuse mode operation additional plasma volume is generated in between the 52 multi jets. These two applicators have been developed and used to plasma treat bacteria contaminated substrates either $55 \mathrm{~mm}$ in diameter or consisting in large $12 \times 12 \mathrm{~cm}^{2}$ samples. The main objective was to assess the antibacterial action of such multi jets for various bacteria including drug resistant strains. Such plasma potentiality was already reported in the literature, but this work addresses simultaneously various plasma delivery strategies for decontamination applications in the perspective of infected and chronic wounds treatment in hospital centers. Indeed, four main plasma exposure protocols have been experienced and demonstrated: plasma treatment of agar samples right after their inoculation with various single bacteria strain, plasma treatment of mature bacterial lawn grown on agar substrates, plasma treatment of multi-contaminated -with three bacteria strains- samples, multi jet treatment in static and scanning modes over extended surface samples.

The second class of multi jet device assessed in this work consists of a bunch of individual millimeter-sized helium jets generated at lower voltage of $2.5 \mathrm{kV}$ peak amplitude, higher repetition rate of 5 to $20 \mathrm{kHz}$. It has been developed to deliver one single jet, and 4, 9 and 13 secondary helium jets. It is reported that for this low voltage applicators, the power and current are quite equally distributed in between each secondary jets (see figure 6), and that this "low voltage applicator" allow for safe and painless multi jets exposure even on uneven, non-flat surfaces (see figure 2). A single jet low voltage plasma jet representative of this second class of plasma device has been used in a pilot clinical tolerance study performed at the Orleans Hospital (CHRO) on superinfected wound bearing patients.

Bacterial decontamination study indicates first that the plasma action is localized in the region where plasma jets impacts and do not diffuse strongly in between the secondary jets regions during plasma jet exposure (see figure 7). This result is a good indication in the perspective of wound treatment as the plasma treatment can be restricted to the zone where bacterial decontamination is required, while non exposing healthy tissues. A time exposure dependent inhibition surface is measured on contaminated sample exposed to multi jets. As the diameter of the multi jets is almost constant, as emerging from same diameter channels drilled in the plasma applicators, two main conclusions results from this measurement. First, since the plasma light emission volume remains constant throughout any exposure time, it is concluded that the plasma light emission cross section observed on the sample surface is not the best indicator to predict the inhibition zone diameter. It is proposed that both plasma generated reactive species accumulation and the combination of these reactive species with transient electric fields inherent with the multi-jets delivery may play together a role in the bacteria decontamination. In addition to the reactive species delivery, the bacteria on the central zone of the plasma jet impact zone may be inactivated during short exposure as exposed to rather intense electric field, while those on the more outer locations will require the accumulation of a larger number of lower strength electric field pulses and lower doses of reactive species.

Complementary, and in the perspective of extended wound treatment, the use of the diffuse mode applicator (see figure 8) or of the rotating (see figure 7), linear (see figure 10) and zigzag (see figure 11) scanning protocols, demonstrates that large surface may be rather homogeneously decontaminated, extending the potentialities of plasma technology for these medical applications. Shorter treatment plasma exposure can indeed be developed on the base of these multi jets scanning applicators. Few square centimeter large contaminated sample are inactivated for a single fraction of only one-minute-long exposure. In the context of patient's wound treatment, such short time exposure is an excellent indication for a highly tolerable therapeutic protocol, and may be envisioned as a daily fractionated treatment. 
Bacterial inactivation was demonstrated for S. aureus, $P$. aeruginosa and drug resistant $S$. aureus, $P$. aeruginosa and E. coli strains collected for patient's wound at Orleans hospital. Not documented in this work, full decontamination was also achieved for S. dysgalactiae and B. subtilis strains collected at Orleans Hospital. This confirms that plasma action has a broad spectrum target approach likely to be applied for various bacteria families, either gram positive or gram negative, even with the same plasma operation mode. It is also demonstrated that plasma multi jets can be a potent bactericidal agent for native or mature bacterial lawn contaminated with a single but also a mix of various pathogens. Similar efficiency was demonstrated for antibiotic-resistant and non-resistant $P$. aeruginosa (see figure 9) as previously reported but for E. coli bacteria and with dielectric barrier discharge applicator [33]. This strengthen the well-known unique status of plasma technology, in comparison with conventional antibiotics drugs, as a broad spectrum and non-systemic, and thus likely presenting low side-effects, therapeutic option.

Finally, the low voltage plasma applicator, was used for the fractionated treatment of five wound bearing patients with the focus on the scoring of the treatment tolerance and toxicity assessment. The plasma applicator was used along few tens of minutes' exposure, by different nurses, and for wounds of various extensions, surface topologies, including necrotic, dry and humid zones. As summarized in section 3.5, the tolerance scoring was excellent with absolutely no pain, skin injury, inflammatory feeling or observed effects. While the study was focused on the tolerance and toxicity of plasma treatment, it was nevertheless observed, even with this limited patient cohort, a trend for the improvement of the tissue status on plasma treated zone in comparison with the non-targeted zone for the same patient. Work is ongoing to assess the tolerance and healing efficiency of plasma multi-jets daily or each other day delivered alone and in combination with dedicated dressings. This work is a new contribution in the development of plasma technology therapy for wound treatment but as expressed in the conclusion of [40], "the possible role of cold atmospheric pressure plasma in clinical multi drug resistant decontamination must be evaluated in clinical trials with repeated plasma treatment embedded in a comprehensive hygienic decontamination concept". This mandatory step is planned in collaboration with CHRO. This work demonstrates that on-demand design of multi jets applicators can be performed for the development of various plasma applicator sizes, shapes with various number and spatial distribution of the multi jets likely covering very extended surfaces.

Author Contributions: Conceptualization, T.M., M.D., S.D., I.G., L.H., C.L.H., J.-M.P., T.P. and E.R.; methodology, T.M., F.B.M., M.D., S.D., I.G., C.L.H., J.-M.P., A.S. and E.R.; investigation, T.M., M.D., S.D., I.G., C.L.H., I.O., C.T. and E.R.; resources, M.D., C.L.H., and T.P.; writing-original draft preparation, T.M., T.P., J.-M.P., and E.R.; writing - review and editing, all co-authors; supervision, M.D, T.P., J.M. P; and E.R.; funding acquisition, C.D., J.-M.P. and E.R. All authors have read and agreed to the published version of the manuscript.

Funding: This research was funded by PEPS-CNRS project 'ACUMULTIPLAS'.

Institutional Review Board Statement: “Ethical review and approval were waived for this study, due to focus of the pilot study on tolerance assessment performed with informed consent of patients and with a radual increase of the plasma exposure time"

Informed Consent Statement: "Informed consent was obtained from all subjects involved in the study."

Data Availability Statement: The data that support the methods and findings of this study are available from the corresponding author upon reasonable request.

Acknowledgments: This work was supported by PEPS-CNRS 'ACUMULTIPLAS', CNRS GDR 2025 'HAPPYBIO'. Authors express their sincere acknowledgments to Dr. João SANTOS SOUSA (LPGP, Université Paris-Saclay, CNRS, 91405 Orsay, France), Dr. Lluis. M. MIR (Institut Gustave Roussy, Metabolic and Systemic Aspects of Oncogenesis (METSY), Université Paris-Saclay, CNRS, 94805 
Villejuif, France), Dr. Thai Hoa CHUNG (Institut Gustave Roussy, Metabolic and Systemic Aspects of Oncogenesis (METSY), Université Paris-Saclay, CNRS, 94805 Villejuif, France) for their contribution in preliminary but key experiments and discussions during the PEPS 'ACUMULTIPLAS's project. I.O. is supported by 'PLASFECT' project funded through the 2nd French-German call for projects on antimicrobial resistance 2020 "One Health: AMR in environmental reservoirs and Colonizing antibiotic-resistant bacteria. A.S. is supported by 'MINIONS' project funded through ARD Centre Val De Loire COSMETOSCIENCES.

Conflicts of Interest: The authors declare no conflict of interest. The funders had no role in the design of the study; in the collection, analyses, or interpretation of data; in the writing of the manuscript, or in the decision to publish the results.

\section{References}

1. M. Laroussi, Nonthermal decontamination of biological media by atmospheric-pressure plasmas: review, analysis, and prospects, IEEE Trans. Plasma Sci., 30, 1409 (2002)

2. M. Moisan, J. Barbeau, S. Moreau, J. Pelletier, M. Tabrizian, L'H. Yahia, Low-temperature sterilization using gas plasmas: a review of the experiments and an analysis of the inactivation mechanisms, Int. J. Pharm., 226, 1 (2001)

3. W.P. MENASCHI, Treatment of surfaces, US patent 3383163 (1968)

4. P.T. JACOBS, S.M. LIN, Gas-plasma sterilization. In: COUGH RL, SHALABY SW. Irradiation of Polymers: fundamentals and technological applications. Washington D.C.: American Chemical Society, (1994)

5. S. Crow and J.H. Smith III, Infection Control and Hospital Epidemiology, Vol. 16, No. 8, 483-487 (1995).

6. M. Deilmann, H. Halfmann, N. Bibinov, J. Wunderlich, P. Awakowicz, Low-pressure microwave plasma sterilization of polyethylene terephthalate bottles, Journal of food protection 71 (10), 2119-2123 (2008)

7. J. Ehlbeck, U. Schnabel, M. Polak, J. Winter, Th. von Woedtke, R. Brandenburg, T. von dem Hagen and K.-D. Weltmann, Low temperature atmospheric pressure plasma sources for microbial decontamination, J. Phys. D: Appl. Phys. 44013002 (2010)

8. Z. Ben Belgacem, G. Carré, E. Charpentier, F. Le-Bras, T. Maho, E. Robert, J.-M. Pouvesle, F. Polidor, S. C. Gangloff, M. Boudifa, M.-P. Gelle, Innovative non-thermal plasma disinfection process inside sealed bags: Assessment of bactericidal and sporicidal effectiveness in regard to current sterilization norms, PLoS One 12 (6), e0180183 (2017)

9. S. Bekeschus, P. Favia, E. Robert, T. von Woedtke, White paper on plasma for medicine and hygiene: Future in plasma health sciences, Plasma Processes and Polymers 16 (1), 1800033 (2019)

10. B. Yadav, A.C. Spinelli, N. N. Misra, Y. Y. Tsui, L.M. McMullen, M.S. Roopesh, Effect of in-package atmospheric cold plasma discharge on microbial safety and quality of ready-to-eat ham in modified atmospheric packaging during storage, Journal of Food Science 85, 4, 1203-1212 (2020)

11. M. Emerald, A. Emerald, L. Emerald, V. Kumar, Perspective of natural products in skincare, Pharmacy \& Pharmacology International Journal 4(3): 72 (2016)

12. F. Capelli, S. Tappi, T. Gritti, A.C. de Aguiar Saldanha Pinheiro, R. Laurita, U. Tylewicz, F. Spataro, G. Braschi, R. Lanciotti, F. Gómez Galindo, V. Siracusa, S. Romani, M. Gherardi, V. Colombo, V. Sambri, P. Rocculi, Decontamination of food packages from SARS-COV-2 RNA with a cold plasma-assisted system, Applied Sciences 11 (9), 4177 (2021)

13. S. Bekeschus, A. Kramer, E. Suffredini, T. Von Woedtke, V. Colombo, Gas plasma technology - An asset to healthcare during viral pandemics such as the COVID-19 crisis?, IEEE Transactions on Radiation and Plasma Medical Sciences 4 (4), 391-399 (2020)

14. G. Fridman, G. Friedman, A. Gutsol, A.B. Shekhter, V.N. Vasilets, A. Fridman, Applied plasma medicine, Plasma processes and polymers 5 (6), 503-533 (2008)

15. M. G. Kong, G. Kroesen, G. Morfill, T. Nosenko, T. Shimizu, J. van Dijk, J.L. Zimmermann, Plasma medicine: an introductory review, New Journal of Physics 11115012 (2009)

16. G. Isbary, G. Morfill, H.U. Schmidt, M. Georgi, K. Ramrath, J. Heinlin, S. Karrer, M. Landthaler, T. Shimizu, B. Steffes, W. Bunk, R. Monetti, J.L. Zimmermann, R. Pompl, W. Stolz, A first prospective randomized controlled trial to decrease bacterial load using cold atmospheric argon plasma on chronic wounds in patients, British Journal of Dermatology 163 (1), 78-82 (2010)

17. A.V. Nastuta, I. Topala, C. Grigoras, V. Pohoata, G. Popa, Stimulation of wound healing by helium atmospheric pressure plasma treatment. J. Phys. D. Appl. Phys. 44, 105204 (2011)

18. S. Emmert, F. Brehmer, H. Hänßle, A. Helmke, N. Mertens, R. Ahmed, D. Simon, D. Wandke, W. Maus-Friedrichs, G. Däschlein, M.P. Schön, W. Viöl, Atmospheric pressure plasma in dermatology: Ulcus treatment and much more. Clin. Plasma Med. 1, 24$29(2013)$

19. E. García-Alcantara, R. López-Callejas, P.R. Morales-Ramírez, R. Peña-Eguiluz, R. Fajardo-Muñoz, A. Mercado-Cabrera, S.R. Barocio, R. Valencia-Alvarado, B.G. Rodríguez-Méndez, A. E. Muñoz-Castro, A. de la Piedad-Beneitez, I. A. Rojas-Olmedo, Accelerated mice skin acute wound healing in vivo by combined treatment of argon and helium plasma needle. Arch. Med. Res. 44, 169-177 (2013)

20. B. Haertel, T. von Woedtke, K.-D. Weltmann, U. Lindequist, Non-thermal atmospheric-pressure plasma possible application in wound healing. Biomol. Ther. (Seoul). 22, 477 (2014)

21. A. Schmidt, S. Bekeschus, K. Wende, B. Vollmar, T. von Woedtke, A cold plasma jet accelerates wound healing in a murine model of full-thickness skin wounds. Exp. Dermatol. 49 (2016) 
22. B. Gweon, K. Kim, W. Choe, J.H. Shin, Therapeutic uses of atmospheric pressure plasma: cancer and wound. In Biomedical Engineering: Frontier Research and Converging Technologies 357-385 (Springer, 2016)

23. C. Douat, P. Escot Bocanegra, S. Dozias, E. Robert, R. Motterlini, Production of carbon monoxide from a He/CO2 plasma jet as a new strategy for therapeutic applications, Plasma Processes and Polymers, e2100069 (2021)

24. M. Vandamme, E. Robert, S. Pesnel, E. Barbosa, S. Dozias, J. Sobilo, S. Lerondel, A. Le Pape, J.-M. Pouvesle, Antitumor effect of plasma treatment on U87 glioma xenografts: preliminary results, Plasma processes and polymers 7 (3-4), $264-273$ (2010)

25. M. Keidar, R. Walk, A. Shashurin, P. Srinivasan, A. Sandler, S. Dasgupta, R. Ravi, R. Guerrero-Preston, B. Trink, Cold plasma selectivity and the possibility of a paradigm shift in cancer therapy, British journal of cancer 105 (9), 1295-1301 (2011)

26. V. Miller, A. Lin, A. Fridman, Why target immune cells for plasma treatment of cancer? Plasma Chemistry and Plasma Processing 36 (1), 259-268 (2016)

27. M. Rasouli, H. Mehdian, K. Hajisharifi, E. Amini, K. Ostrikov, E. Robert, Plasma activated medium induces apoptosis in chemotherapy-resistant ovarian cancer cells: high selectivity and synergy with carboplatin, Plasma Processes and Polymers, e2100074 (2021)

28. L. Brullé, M. Vandamme, D. Riès, E. Martel, E. Robert, S. Lerondel, V. Trichet, S. Richard, J.-M. Pouvesle, A. Le Pape, Effects of a non-thermal plasma treatment alone or in combination with gemcitabine in a MIA PaCa2-luc orthotopic pancreatic carcinoma model, PloS one 7 (12), e52653 (2012)

29. J. Schlegel, J. Köritzer, V. Boxhammer, Plasma in cancer treatment, Clinical Plasma Medicine 1 (2), $2-7$ (2013)

30. S. Bekeschus, K. Masur, J. Kolata, K. Wende, A. Schmidt, L. Bundscherer, A. M. Barton, A. Kramer, B. Bröker, K.-D. Weltmann, Human mononuclear cell survival and proliferation is modulated by cold atmospheric plasma jet, Plasma Processes and Polymers 10 (8), 706-713 (2013)

31. E.J. Szili, J.S. Oh, H. Fukuhara, R. Bhatia, N. Gaur, C.K. Nguyen, S.H. Hong, S. Ito, K. Ogawa, C. Kawada, T. Shuin, M. Tsuda, M. Furihata, A. Kurabayashi, H. Furuta, M.Ito, K. Inoue, A. Hatta, R.D. Short, Modelling the helium plasma jet delivery of reactive species into a 3D cancer tumour, Plasma Sources Science and Technology 27 (1), 014001 (2017)

32. P. Brun, G. Bernabè, C. Marchiori, M. Scarpa, M. Zuin, R. Cavazzana, B. Zaniol, E. Martines, Antibacterial efficacy and mechanisms of action of low power atmospheric pressure cold plasma: membrane permeability, biofilm penetration and antimicrobial sensitization, Journal of Applied Microbiology 125, 398-408 (2018)

33. A. Sakudo, T. Misawa, Antibiotic-Resistant and Non-Resistant Bacteria Display Similar Susceptibility to Dielectric Barrier Discharge Plasma, Int. J. Mol. Sci., 21(17), 6326 (2020)

34. S.G. Joshi, M. Paff, G. Friedman, G Fridman, A. Fridman, A.D. Brooks, Control of methicillin-resistant Staphylococcus aureus in planktonic form and biofilms: a biocidal efficacy study of nonthermal dielectric-barrier discharge plasma, Am J Infect Control., 38(4):293-301 (2010)

35. T.G. Klämpfl, T. Shimizu, S. Koch, M. Balden, S. Gemein, Y.-F. Li, A. Mitra, J.L. Zimmermann, J. Gebel, G.E. Morfill, H.-U. Schmidt, Decontamination of Nosocomial Bacteria Including Clostridium Difficile Spores on Dry Inanimate Surface by Cold Atmospheric Plasma, Plasma Processes and Polymers 11, 10, 974-984 (2014)

36. Y. He, C. Ding, T. Jin, Y. Fan, Z. Wu, M. Sun, K. Wang, T. JI, Sensitivity of two drug-resistant bacteria to low-temperature air plasma in catheter-associated urinary tract infections under different environments, Plasma Sci. Technol. 22 065502 (2020)

37. A. Stancampiano, T. Gallingani, M. Gherardi, Z. Machala, P. Maguire, V. Colombo, J.-M. Pouvesle, E. Robert, Plasma and aerosols: Challenges, opportunities and perspectives, Applied Sciences 9 (18), 3861 (2019)

38. A. Bisag, P. Isabelli, R. Laurita, C. Bucci, F. Capelli, G. Dirani, M. Gherardi, G. Laghi, A. Paglianti, V. Sambri, V. Colombo, Cold atmospheric plasma inactivation of aerosolized microdroplets containing bacteria and purified SARS-CoV-2 RNA to contrast airborne indoor transmission, Plasma Processes and Polymers 17 (10), 2000154 (2020)

39. W. Chiappim, A. Sampaio, F. Miranda, G. Petraconi, A. da Silva Sobrinho, P.Cardoso, K. Kostov, C. Koga-Ito, R. Pessoa, Nebulized plasma-activated water has an effective antimicrobial effect on medically relevant microbial species and maintains its physicochemical properties in tube lengths from 0.1 up to $1.0 \mathrm{~m}$, Plasma Processes and Polymers, e2100010 (2021)

40. G. Daeschlein, M. Napp, S. Lutze, A. Arnold, S. von Podewils, D. Guembel, M. Jünger, Skin and wound decontamination of multidrug-resistant bacteria by cold atmospheric plasma coagulation, J Dtsch Dermatol Ges.,13(2):143-50 (2015)

41. J. Heinlin, G. Isbary, W. Stolz, G. Morfill, M. Landthaler, T. Shimizu, B. Steffes, T. Nosenko, J.L. Zimmermann, S. Karrer, Plasma applications in medicine with a special focus on dermatology, J Eur Acad Dermatol Venereol., 25(1):1-11 (2011)

42. J.-M. Pouvesle, C. Cachoncinlle, R. Viladrosa, A. Khacef, E. Robert, S. Dozias, Transient plasma ball generation system at long distance, US Patent 8,482,206 (2013)

43. J.-M. Pouvesle, E. Robert, S. Dozias, M. Hugnot, V. Sarron, T. Darny, Method and device for generating a plurality of coldplasma jets at atmospheric pressure, US Patent 10,420,852 (2019)

44. A.V. Omran, G. Busco, L. Ridou, S. Dozias, C. Grillon, J.-M. Pouvesle, E. Robert, Cold atmospheric single plasma jet for RONS delivery on large biological surfaces, Plasma Sources Science and Technology 29 (10), 105002 (2020)

45. E. Robert, T. Darny, S. Dozias, S. Iseni, J.-M. Pouvesle, New insights on the propagation of pulsed atmospheric plasma streams: From single jet to multi jet arrays, Physics of plasmas 22 (12), 122007 (2015)

46. A.M. Lietz, X. Damany, E. Robert, J.-M. Pouvesle, M.J. Kushner, Ionization wave propagation in an atmospheric pressure plasma multi-jet, Plasma Sources Science and Technology 28 (12), 125009 (2019)

47. K.G. Kostov, M. Machida, V. Prysiazhnyi, R.Y. Honda, Transfer of a cold atmospheric pressure plasma jet through a long flexible plastic tube, Plasma Sources Science and Technology 24 (2), 025038 (2015) 
48. T.H. Chung, A. Stancampiano, K. Sklias, K. Gazeli, F.M. André, S. Dozias, C. Douat, J.-M. Pouvesle, J. Santos Sousa, E. Robert, L.M. Mir, Cell electropermeabilisation enhancement by non-thermal-plasma-treated pbs, Cancers 12 (1), 219 (2020)

49. E.J. Szili, J.S. Oh, S.H. Hong, A. Hatta, R.D. Short, Probing the transport of plasma- generated RONS in an agarose target as surrogate for real tissue: dependency on time, distance and material composition, Journal of Physics D: Applied Physics, 48 (20), 202001 (2015)

50. T. Kawasaki, F. Mitsugi F, K. Koga, M. Shiratani M, Local supply of reactive oxygen species into a tissue model by atmosphericpressure plasma-jet exposure, J. Appl. Phys. 125213303 (2019)

51. M. Vandamme, E. Robert, S. Lerondel, V. Sarron, D. Ries, S. Dozias, J. Sobilo, D. Gosset, C. Kieda, B. Legrain, J.-M. Pouvesle, A. Le Pape, ROS implication in a new antitumor strategy based on non-thermal plasma, International journal of cancer 130 (9), 2185-2194 (2012)

52. D.B. Graves, The emerging role of reactive oxygen and nitrogen species in redox biology and some implications for plasma applications to medicine and biology, Journal of Physics D: Applied Physics 45 (26), 263001 (2012)

53. A. Sobota, O. Guaitella, E. Garcia-Caurel, Experimentally obtained values of electric field of an atmospheric pressure plasma jet impinging on a dielectric surface, Journal of Physics D: Applied Physics 46 (37), 372001 (2013)

54. K. Orr, Y. Tang, M.S. Simeni, D. Van Den Bekerom, I.V. Adamovich, Measurements of electric field in an atmospheric pressure helium plasma jet by the E-FISH method, Plasma Sources Science and Technology 29 (3), 035019 (2020)

55. A. Bourdon, T. Darny, F. Pechereau, J.-M. Pouvesle, P. Viegas, S. Iséni, E.Robert, Numerical and experimental study of the dynamics of a $\mu$ s helium plasma gun discharge with various amounts of N2 admixture, Plasma Sources Science and Technology 25 (3), 035002 (2016)

56. Z. Xiong, M.J. Kushner, Atmospheric pressure ionization waves propagating through a flexible high aspect ratio capillary channel and impinging upon a target, Plasma Sources Science and Technology 21 (3), 034001 (2012)

57. S. Dozias, J.-M. Pouvesle, E. Robert, Comment on 'Mapping the electric field vector of guided ionization waves at atmospheric pressure' 2020 Plasma Res. Express 2 025014, Plasma Research Express 3 (3), 038001 (2021)

58. V. Vijayarangan, A. Delalande, S. Dozias, J.-M. Pouvesle, E. Robert, C. Pichon, New insights on molecular internalization and drug delivery following plasma jet exposures, International Journal of Pharmaceutics 589, 119874 (2020)

59. J. Van der Paal, G. Fridman, A. Bogaerts, Ceramide cross-linking leads to pore formation: Potential mechanism behind CAP enhancement of transdermal drug delivery., Plasma Process. Polym. 208, 23. (2019)

60. M. Jinno, Y. Ikeda, H. Motomura, Y. Kido, and S. Satoh, Investigation of plasma induced electrical and chemical factors and their contribution processes to plasma gene transfection, Arch. Biochem. Biophys., 605, 59-66, (2016)

61. Q. Zhang, J. Zhuang, T. von Woedtke, J. F. Kolb, J. Zhang, J. Fang, K.-D. Weltmann, Synergistic antibacterial effects of treatments with low temperature plasma jet and pulsed electric fields, Appl. Phys. Lett. 105, 104103 (2014)

62 .

L.M. Mir, Recommendations for plasma multi-jets usage: summary of pilot mouse study, in French, private communication (2018) 